\title{
Waterproofing material for protection of underground structures
}

\author{
Olga Lyapidevskaya* \\ Moscow State University of Civil Engineering, Yaroslavskoe Shosse, 26, Moscow, 129337, Russia
}

\begin{abstract}
The article deals with the problem of increasing the durability of underground and buried buildings. One of the methods of solving this problem is ensuring the reliable protection of underground structures from the effects of water of different origin. Among the existing waterproofing coatings, mineral-based compositions are the most effective. However, the main disadvantage of such systems is the low crack resistance of hard coatings, which limits their applicability. We have made an attempt to develop a cement-based waterproofing material that would have high elasticity, strength, crack resistance and adhesion to a concrete base. We have conducted studies to justify the possibility of obtaining an effective waterproofing material by including microsilica and ethylene vinyl acetate in the mix. The optimal composition of the material was worked out. On the basis of the experimental data, the main physical and mechanical properties of the material were established. Based on the obtained results, it was found that the resulting material had high physical and mechanical characteristics and could be recommended for the protection of concrete structures used in underground construction.
\end{abstract}

\section{Introduction}

The development of the underground space of large cities is one of the main directions of modern construction. The erection of underground and buried structures represents the highest class of complexity and requires a special approach to the design, construction, protection and maintenance. In this regard, improving the reliability and durability of underground structures is particularly relevant. One of the factors affecting the durability of underground structures is the impact of infiltration and groundwater, as well as anthropogenic sources [1].

The most important measure for the protection of bearing and enclosing underground structures is the arrangement of high-quality waterproofing systems. Particular attention should be paid to the choice of a waterproofing coating. Various types of waterproofing coatings based on bitumen, bitumen-polymer and polymer roll and mastic materials; steel and plastic sheets, bentonite mats, as well as mineral-based compositions are used to protect underground structures [2-7].

Nowadays, waterproofing coating compositions on cement base are widely used. Among the advantages of these materials the following ones should be mentioned: the possibility of applying to the concrete base in the early stages after concrete has been laid,

*Corresponding author: olga.lyapidevskaya@ inbox.ru 
the formation of a seamless coating, no need to erect the guard wall, the possibility of using both in the construction of new and in repair of old structures, as well as environmental safety $[2,8]$.

However, along with the indisputable advantages over other coatings, cement compositions can only be used in the construction of underground objects that do not experience significant temperature effects and various deformations. Alternate freezing and thawing, temperature drops cause the appearance of cracks, which entails the coatings destruction. The use of rigid cement coatings is permissible only when the concrete has maximum cracks opening width no greater than $0.3 \mathrm{~mm}$ [9].

In order to increase the elasticity of the coatings, waterproofing cement compositions modified with acrylic emulsion have been developed; they are able to provide crack bridging up to $0.5 \mathrm{~mm}[2,10]$. However, such compositions have low frost resistance and adhesion to the concrete surface. Dry adhesive mixtures with enhanced adhesion characteristics (for example, masonry and tile mortars) using various redispersible powders are known [11]. But in our country, waterproofing cement materials for underground construction, which contain redispersible powders, are not fully studied and therefore are not widely used.

Thus, the analysis of materials used in waterproofing systems indicates the need to develop an effective elastic mineral-based coating material to protect the underground parts of buildings and structures, which would be devoid of the above disadvantages.

\section{Materials and theoretical analysis}

We have made an attempt to develop a waterproofing dry mixture, which includes a mineral binder, fine aggregate, filling compound and additives.

It was assumed that the use of Portland cement, quartz sand, microsilica, redispersible powder, superplasticizer and water-retaining agent will make it possible to produce an effective protective material.

For the research we used Portland cement class CEM-I $42.5 \mathrm{~N}$.

In order to reduce shrinkage deformations of the cement stone and improve its physical and mechanical characteristics by creating a rigid framework and compaction the structure, we used fine quartz sand of fractions $0.16-0.63 \mathrm{~mm}$ as aggregate.

Amorphous microsilica MS 85 was used as an active mineral additive. The introduction of microsilica increases the strength and watertightness of the mortar due to the reaction of interaction of silica dioxide $\mathrm{SiO}_{2}$ and calcium hydroxide $\mathrm{Ca}(\mathrm{OH})_{2}$ with the formation of low-basic hydro silicates, which compact the structure of cement stone [12,13]. Considering the high specific surface of microsilica $(18000 \mathrm{~cm} 2 / \mathrm{g})$, a plasticizer was used to reduce the water-solid ratio (W/S) and achieve the desired effect. A superplasticizer Melflux $2561 \mathrm{~F}$ polycarboxylate was used as a plasticizing additive. The action of polycarboxylate is based on the mechanism of steric repulsion of side chains of adsorbed molecules [14, 15].

In order to increase the elasticity and adhesion characteristics of the material, an additive of ethylene vinyl acetate (EVA) Mowilith Pulver DM 2072 R was used. This additive is a dry redispersible polymer powder of yellow color, obtained by the method of spray drying of latex emulsion. When mixed with water, the powder forms aqueous polymer dispersion $[16,17]$. Due to the elastic polymer bonds, which EVA forms between the particles of the mortar mixture, the mortar has increased tensile strength and crack resistance. After mixing the dry mixture with water redispersible powder dissolves, turning into an emulsion. As the binder hardens and the fraction of the aqueous phase decreases, the polymer from the emulsion coagulates, being distributed on the surface of solid particles in the form of polymer films. The polymer itself does not chemically interact with cement and 
other components, but forms flexible bonds, giving the mortar stone increased elasticity. After the formation of a single membrane in the mortar, the tensile strength begins to form in the material and the adhesion strength increases. The tensile strength of the films and their adhesion to solid particles can reach $5 \mathrm{MPa}$ [17], which contributes to the growth of the tensile strength of the mortar. Due to its elasticity, the redispersible powder retains polymer "bridges" even in those areas where, for whatever reason, the existing chemical bonds between the mineral components of the two bodies have not been formed or broken.

When applying the coating material to a concrete base, water is absorbed from the mortar mixture, which can lead to shrinkage cracks. To retain water in a thin layer by the formation of stable aqua complexes, a cellulose-based water-retaining agent was used methylcellulose Tylose H 300 p 2, which is a fine white powder.

\section{Methods}

In order to develop the optimal composition of the waterproofing coating, the influence of the percentage of different components on the basic physical and mechanical properties of the coating material was studied. Considering the mutual influence of several factors, the studies were carried out using mathematical methods for planning an experiment.

The following parameters were taken as independent variables: consumption of microsilica (MS) and consumption of the additive EVA (in \% by weight of cement). The compressive strength $\left(\mathrm{R}_{\mathrm{c}}, \mathrm{MPa}\right)$ and the adhesion strength of the coating to the concrete base $\left(R_{a}, M P a\right)$ were taken as optimization parameters.

For all compositions the following parameters were accepted as permanent:

- materials consumption (\% by weight of cement): fine aggregate (quartz sand) - 36,7; superplasticizer $-0,35$; water-retaining agent $-0,2$;

- curing temperature $+20^{\circ} \mathrm{C}$;

- humidity $-98 \%$.

As a result of the experiment and data processing, the dependences shown in figure 1, 2 were obtained.

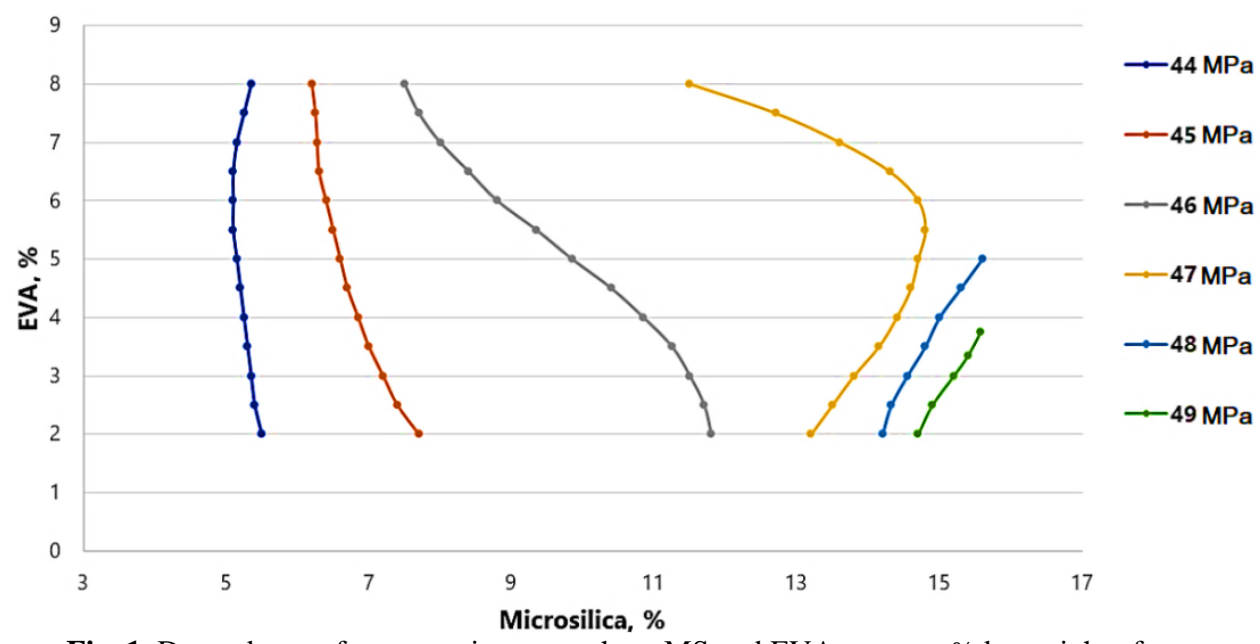

Fig. 1. Dependence of compressive strength on MS and EVA content, \% by weight of cement. 


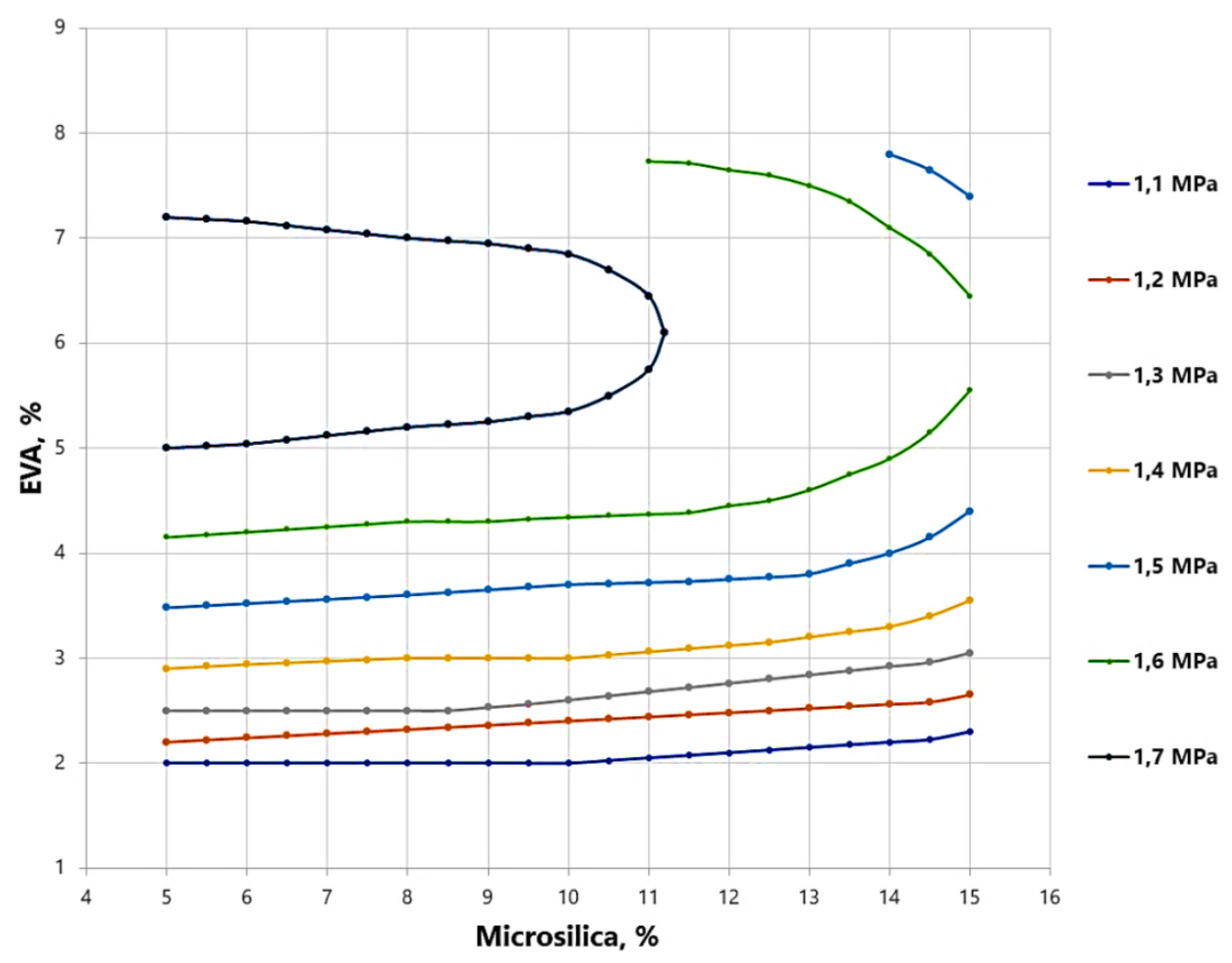

Fig. 2. Dependence of adhesion strength on MS and EVA content, \% by weight of cement.

The following conclusions can be drawn from the analysis of the obtained results.

With the introduction of microsilica (ceteris paribus) the compressive strength increases in direct proportion to the microsilica content ( $\%$ by weight of cement): when $\mathrm{MS}=5 \% \mathrm{R}_{\mathrm{c}}$ $=44.5 \mathrm{MPa}$, when $\mathrm{MS}=10 \% \mathrm{R}_{\mathrm{c}}=48.4 \mathrm{MPa}$, when $\mathrm{MS}=15 \% \mathrm{R}_{\mathrm{c}}=54.3 \mathrm{MPa}$. The adhesion strength, on the contrary, decreases with increasing of microsilica content: from 1.2 $\mathrm{MPa}$ when $\mathrm{MS}=5 \%$ to $1.1 \mathrm{MPa}$ when $\mathrm{MS}=15 \%$.

The introduction of the redispersible additive causes a significant increase of the adhesion strength to the concrete base (ceteris paribus): when EVA $=2 \% \mathrm{R}_{\mathrm{a}}=1.3 \mathrm{MPa}$, when $\mathrm{EVA}=5 \% \mathrm{R}_{\mathrm{a}}=1.47 \mathrm{MPa}$, when $\mathrm{EVA}=10 \% \mathrm{R}_{\mathrm{a}}=1.71 \mathrm{MPa}$. With a further increase of the redispersible additive consumption, the adhesion strength varies slightly. The compressive strength rises with increasing redispersible powder consumption from 2 to $5 \%$ (from 42.4 to $47 \mathrm{MPa}$ ); however, with a further growing of EVA consumption, it is going down.

Thus, when processing the results, it turned out that the best properties had a composition with the following content of components ( $\%$ by weight of cement): quartz sand - 36.7; microsilica - 10; redispersible powder -5 ; superplasticizer $-0,35$; waterretaining agent $-0,2$.

These results were achieved with a water-solid ratio of 0.32 . This composition was recognized as optimal (table 1). 
Table 1. The optimal composition of waterproofing coating material.

\begin{tabular}{lc}
\hline Component & Consumption, kg \\
\hline Portland cement & 660 \\
Quartz sand & 241 \\
Microsilica & 66 \\
Redispersible powder & 33 \\
Superplasticizer & 2,3 \\
Water-retaining agent & 1,3 \\
\multicolumn{2}{c}{ Water-solid ratio W/S $=0,32$} \\
\hline
\end{tabular}

\section{Results}

The main physical and mechanical characteristics (water-retaining capacity, compressive strength, tensile strength and watertightness) of the waterproofing cement-based coating material with additives of microsilica and ethylene vinyl acetate were carried out according to standard methods [18-22]. Samples were stored under normal conditions: at temperature $(20 \pm 2)^{\circ} \mathrm{C}$, atmospheric pressure and relative humidity $(95 \pm 5) \%$.

Adhesive strength, water permeability and static crack bridging ability were determined according to EN 14981 [23].

Classes of waterproofing material on the crack bridging capacity were established in accordance with EN 1504-2 [24]. Test conditions were adopted according to method A (continuous crack bridging) according to DIN EN 1062-7 [25] (table 2).

Table 2. Test conditions by the A method ${ }^{\mathrm{a}}$.

\begin{tabular}{ccc}
\hline Class & $\begin{array}{c}\text { Static crack-bridging } \\
\text { expressed as maximum } \\
\text { crack width, mm }\end{array}$ & $\begin{array}{c}\text { Скорость } \\
\text { раскрытия } \\
\text { трещин, мм/мин }\end{array}$ \\
\hline A1 & $>0,100$ & - \\
A2 & $>0,250$ & 0,05 \\
A3 & $>0,500$ & 0,05 \\
A4 & $>1,250$ & 0,5 \\
A5 & $>2,500$ & 0,5
\end{tabular}

${ }^{\mathrm{a}}$ Note. The test temperature recommended for classes $\mathrm{A} 2$ - A5 is $-10^{\circ} \mathrm{C}$, for class A1 $21^{\circ} \mathrm{C}$.

Samples made from an optimized composition at the age of 28 days showed the best results in compressive strength, tensile strength and adhesive strength to a concrete base. Wateretightness tests (by the "wet spot" method) showed a result corresponding to W14 (table 3).

Thus, according to the data given in table 3 , it can be concluded that the developed material meets the requirements of Russian and foreign standards in terms of physical, mechanical and technical characteristics. 
Table 3. Physical, mechanical and technical characteristics of the developed composition.

\begin{tabular}{|c|c|c|c|}
\hline Properties & Value & $\begin{array}{c}\text { Values in accordance } \\
\text { with the requirements } \\
\text { of the standards }\end{array}$ & Standards \\
\hline Water-retaining capacity, $\%$ & 95 & Not less 90 & GOST R 56703 \\
\hline Compressive strength, $\mathrm{MPa}$ & 46 & $\begin{array}{l}\text { Waterproofing } \\
\text { coating should not } \\
\text { reduce the design }\end{array}$ & GOST R 56703 \\
\hline Tensile strength, $\mathrm{MPa}$ & 1.3 & $\begin{array}{l}\text { strength of the } \\
\text { protected concrete }\end{array}$ & GOST R 56703 \\
\hline Adhesive strength, $\mathrm{MPa}$ & 1.7 & more than 0.5 & $\begin{array}{l}\text { EN 14891, } \\
\text { GOST } 31357\end{array}$ \\
\hline Crack bridging, $\mathrm{mm}$ & 0.8 & more than 0.75 & EN 14891 \\
\hline $\begin{array}{l}\text { Class on the crack bridging } \\
\text { capacity }\end{array}$ & A3 & more than $0.5 \mathrm{~mm}$ & EN 1504-2 \\
\hline Watertightness, atm, grade & W14 & not less than W6 & GOST 31357 \\
\hline Consumption per $1 \mathrm{~m}^{2}, \mathrm{~kg}$ & $1.5-1.8$ & - & - \\
\hline
\end{tabular}

\section{Conclusion}

The test results showed that the waterproofing material developed on the basis of cement with additives of microsilica and ethylene vinyl acetate has high tensile and compression strength, adhesion strength to the concrete base, as well as high watertightness and can be recommended as a protective coating for concrete structures used in underground construction.

\section{References}

1. Potapov A D and Chernyshev S N 2013 Vestnik MGSU 1 159-168

2. Shilin A A, Zajcev M V, Zolotarev I A and Lyapidevskaya O B 2003 Waterproofing of Underground and Buried Structures in Construction and Repair (Tver: Russian trademark) pp 25-100

3. Anderson B. 1984 Underground Space 8-2 21-29

4. Meshkov P I and Mokin V A 2001 Construction Materials 4 12-13

5. Steele, J. and Steele, C. 1999 Journal of protective coatings and linings 16(7) 29-35

6. Mendes P, Lopes J G, Brito J and João F 2014 Performance of Constructed Facilities 28(2) 242-249

7. Musienko S P 2007 Geotechnical mechanics 73 164-170

8. Neville A 1997 Concrete International 11 9-12

9. SR 63.13330.2012 Concrete and Reinforced Concrete Structures. Principal rules

10. Swamy R N. Suryavanshi A K and Tanikawa S. 1998 ACI Materials Journal 95 101112.

11. Misnikov O S, Pukhova O V, Belugin D Yu and Ascheulnikov P F 2004 Construction Materials 10 2-5

12. Kaprielov S S 1995 Concrete and reinforced concrete 4 16-20

13. Maage M and Sellevold E J 1987 Concrete International 9 39-43 
14. Ohta A, Sugiyama T and Tanaka Y 1997 Fluidizing Mechanism and Application of Polycarboxylate-Based Superplasticizers Proc. 5th CANMET/ACI Int. Conf. on Advances in Concrete Science Techn. (Rome, Italy) pp 173-19

15. Malhotra V V Innovative 1997 Applications of Superplasticizers in Concrete Proc. 5th CANMET/ACI Int. Conf. on Advances in Concrete Science Techn. (Rome, Italy) pp 271314

16. Udodov S A and Gish M R 2015 Influence of the dosage of the redispersible powder on polymer localization and deformation properties of the solution Proc. of Kuban State Technical University (Krasnodar, Russia), Vol 9 pp 164-174

17. Zakhezin A E, Chernykh T N, Trofimov B Ya and Kramar L Ya 2004 Construction Materials 10 6-8

18. GOST 31356-2013 Dry building cement binder mixes. Test methods

19. GOST 10180-2012 Concretes. Methods for strength determination using reference specimens

20. GOST 12730.5-84 Concretes. Methods for determination of watertightness

21. GOST 31357-2007 Dry building cement binder mixes. General specifications

22. GOST R 56703-2015 Dry building in-depth waterproofing capillary mixes based on cement binder. Specifications

23. DIN EN 14891-2013 Liquid-applied water impermeable products for use beneath ceramic tiling bonded with adhesives - Requirements, test methods, evaluation of conformity, classification and designation

24. EN 1504-2:2009 Products and systems for the protection and repair of concrete structures. Definitions, requirements, quality control and evaluation of conformity. Part 2. Surface protection systems for concrete

25. DIN EN 1062-7:2004 Paints and varnishes - Coating materials and coating systems for exterior masonry and concrete. Part 7: Determination of crack bridging properties 